\title{
Prima hartă a zăcămintelor de sare din România (1780). Toponimele corespondente actuale ${ }^{\dagger}$
}

\author{
Dinu Moscal* \\ Departamentul de Cercetare Interdisciplinar - Domeniul Socio-Uman, Universitatea „Alexandru Ioan Cuza”, \\ Str. Lascăr Catargi 54, 700107 Iași, România \\ Institutul de Filologie Română „A. Philippide”, Str. Th. Codrescu 2, 700481 Iași, România
}

\author{
Despre articol \\ Istoric: \\ Primit 29 octombrie 2017 \\ Acceptat 20 noiembrie 2017 \\ Publicat 30 noiembrie 2017 \\ Cuvinte-cheie: \\ zăcăminte de sare \\ izvoare saline \\ Carpați \\ toponimie \\ harta lui Fichtel (1780)
}

\begin{abstract}
Rezumat
Istoricul exploatării sării în zona arcului carpatic reprezintă încă un deziderat pentru anumite perioade ale provinciilor istorice ale României, deși s-au scris relativ multe lucrări pe această temă. Harta de la 1780 a zăcămintelor de sare din arcul carpatic reprezintă una dintre realizările importante în acest domeniu. Unul dintre lucrurile necesare acestui istoric este identificarea locurilor de unde se extrage sau s-a extras sare. După un scurt istoric al atestărilor primare legate de exploatarea sării pe teritoriul României, lucrarea de față prezintă contribuția lui Fichtel (1780) în identificarea zăcămintelor de sare din acest spațiu. Actualizarea toponimelor din hartă nu prezintă dificultăți pentru provinciile istorice Moldova și Valahia, însă nu la fel este și în cazul toponimelor din Transilvania, nomenclatura din perioada dominației maghiare (pînă în 1918) fiind în mare parte schimbată începînd cu anul 1919. Pentru toate acestea s-au dat corespondentele din nomenclatura actuală. Lucrarea oferă o actualizare a localizării izvoarelor, fîntînilor și sedimentelor de sare identificate de Fichtel, prin identificarea toponimelor corespondente actuale pentru cele indicate în hartă.
\end{abstract}

\section{Scurt istoric}

Zăcămintele de sare din arcul carpatic sînt cele mai mari din Europa, astfel că interesul pentru acestea nu s-a limitat la populația autohtonă, exploatarea ei fiind unul dintre obiectivele principale ale imperiilor care au dominat pentru un anumit timp cel puțin o parte din aceste locuri. Primele informații scrise referitoare la exploatarea sării din arcul carpatic provin din timpul Daciei Romane. Importanța sării este indicată de faptul că exploatarea ei era un privilegiu imperial și că împăratul arenda salinele unor funcționari romani (conductores), adesea împreună cu drepturile de pășunare, uneori și cel al comercializării sării exploatate, după cum arată sursele epigrafice de la începutul secolului al III-lea e.n.: „conductor pascui, salinarum et commerciorum” (CIL III, 1209 [IDR III/5, 443]) sau „conductor pascui et salinarum” (CIL III, 1363 [IDR III/3, 119]; Dana \& Zăgreanu, 2013, p. 28-32, cf. și Mihăilescu-Bîrliba, 2016, p. 57; Fischer, 1921, p. 71; cf. și Christescu, 2004, p. 49), dar și numai „conductor salinarum” (IDR III/4, 248; Piso, 20042005, p. 179-182, cf. și Mihăilescu-Bîrliba, 2016, p. 55-57). Modul de administrare a exploatării sării de către romani nu ne este cunoscut decît într-o mică măsură (cf. Wollmann, 1996, p. 248-249), însă este de presupus că aceștia aveau foarte probabil și o hartă sau un repertoriu al locurilor din care se extrăgea sau se putea extrage sare. Cert este că singura atestare a unui loc de exploatare a sării din această perioadă este cea din Tabula Peutingeriana, unde apare indicaţia în ablativ Salinis (pe hartă în ordinea Blandiana - Apula - Brucla - Salinis - Potavissa - Napoca), notată pe cel mai important drum roman din Dacia, acesta traversînd o zonă cu valoroase resurse naturale. Toponimul a fost însă dificil de localizat, chiar și

\footnotetext{
${ }^{\dagger}$ Această lucrare a fost realizată cu sprijinul unui grant al Ministerului Cercetării şi Inovării, CNCSUEFISCDI, număr proiect 151/2017, PN-III-P4-ID-PCE-2016-0759, în cadrul proiectului PNCDI III.

*Adresă de corespondență: dinu.moscal@gmail.com.
} 
pentru Theodor Mommsen, care atrage atenția că nu poate fi vorba despre Turda, așa cum se crezuse pînă atunci (Zamosius, 1593, p. 78; Opitz, 2009, p. 801, 803; Ackner \& Müller, 1865, p. 138). El îl identifică cu Felvincz, adică Vințul de Sus, astăzi Unirea, județul Alba (cIl III, p. 172, 177), și nu cu Ocna Mureș și Uioara de Sus, situate de cealaltă parte a rîului Mureș. Mommsen aduce în discuție localizarea corectă, Maros-Újvár_care corespunde localităţilor actuale Ocna Mureș și Uioara de Sus—, însă o menționează doar ca punct de referință pentru Felvincz: „Felvincz [...] a salinis quæ etiamnunc durant ad vicum proximum Maros-Ujvár” (CIL III, p. 177). Corespondența Salinis-Maros-Újvár-Ocna Mureș și Uioara de Sus este confirmată prin urmele exploatării romane găsite aici, atestate întîi de Ackner (1856, p. 23; vezi şi Christescu, 2004, p. 49; Wollmann, 1996, p. 241).

Referiri la sarea și exploatarea ei în actualul spațiu al României au apărut în diverse surse, începînd cu anul 892 (CDEM I, p. 52; vezi și Maghiar \& Olteanu, 1970, p. 97 ș.u.), însuși primul document din epoca feudală referitor la Trasilvania, din anul 1075, este unul legat de ocnele de sare (DIR,C I, p. 1). Din vasta bibliografie pe această temă menționăm aici doar cîteva lucrări cu caracter general în privința istoricului exploatării sării și a repercusiunilor la nivel economic și social în spaţiul românesc: Doboşi (1951), Pascu (1986, p. 246-259), Vitcu (1987), Wollmann (1996), Ciobanu (2002). Prima hartă a salinelor și a sedimentelor de sare din România—focalizată pe spațiul intracarpatic, Transilvania—apare abia în timpul dominației Imperiului Austro-Ungar (printre drepturile regale ale imperiului era și cel al exploatării sării), în studiul lui Fichtel (1780), citat cu regularitate în lucrările de specialitate. Deși localizarea salinelor și a sedimentelor de sare nu ridică dificultăţi comparabile cu cazul din Taubula Peutingeriana (Saline e identificat prin Turda și la Fichtel, 1780, p. 89), toponimele indicate nu sînt întotdeauna ușor de identificat în cadrul nomenclaturii actuale. Excepție fac cele din spațiul extracarpatic, unde este vorba doar despre transliterări. Obiectivul prezentei lucrări este corelarea toponimelor indicate de Fichtel—notate de cele mai multe ori prin corespondente maghiare sau, uneori, germane-cu toponimele actuale. Unele dintre acestea vor fi utile și în consultarea lucrărilor publicate înainte de 1918, de exemplu Ackner (1856), Ackner \& Müller (1865) sau Gooss (1876, p. 264-330).

\section{Harta lui Fichtel}

Studiul mineralogului Fichtel este prima lucrare notabilă dedicată zăcămintelor de sare din România, chiar dacă spațiul extracarpatic este reprezentat doar prin ocnele cele mai importante. Gradul înalt de exactitate al datelor oferite se datorează cu siguranță anchetei directe (Fichtel, 1780, p. 6-7). În plus, lucrarea este și un raport pentru curtea de la Viena, făcut pentru organizarea exploatării sării în Transilvania de către Imperiul Austro-Ungar. Autorul chiar scoate în evidență importanța economică a sării, considerînd că este mai importantă decît aurul din Transilvania: „das Salz füllet auch den Seckel des Staats weit reichlicher, als selbst die siebenbürgische Golderzeugung" (Fichtel, 1780, p. 6-7).

În hartă sînt localizate ocnele în construcție, sedimentele neexploatate („Salzspurien”), fîntînile și izvoarele de apă sărată, însă nu și existența drobilor de sare („Salzlecke”), care nu este considerată relevantă în privința cantității de sare din locurile respective (Fichtel, 1780, p. 29). Omiterea intenționată a prezenței acestora este ușor de explicat, obiectivul final al hărții fiind exploatarea eficientă a sării. Printre precizările legate de harta zăcămintelor de sare apare și o corectare a graniței dintre Moldova și Polonia, care în hărțile anterioare, afirmă Fichtel, era cu 15-20 de mile germane mai avansată spre sud-est, pe limita ce întîlnește rîul Nistru.

În ceea ce privește salinele în exploatare, cele mai importante sînt descrise într-o subsecțiune separată, unele dintre ele în subsecțiuni speciale (Ocna Dej și Ocna Sibiului în $₫ 8$, respectiv $§ 9$ ), ele fiind enumerate împreună cu celelalte pe regiuni în subsecțiunile următoare $(\$ 10-\$ 13)$, referințe punctuale pentru diverse aspecte apărînd în întreg studiul. Trebuie remarcat faptul că obiectivul hărții îl constituie reprezentarea zăcămintelor neexploatate, deoarece harta, ca și studiul, vizează extinderea exploatării sării, iar acestea sînt reprezentate prin simboluri pentru trei categorii: ocne în construcție (pătrat cu suprafața verde), sedimente de sare neexploatate (cerc cu suprafața verde) și surse de apă sărată, adică fîntînile și izvoarele (cerc 
cu suprafața roșie). Astfel, despre Visakna, adică Ocna Sibiului, autorul spune că a numărat cinsprezece ocne, la care se adaugă cele în construcție (Fichtel, 1780, p. 89-90), însă în hartă apar simbolurile pentru ocne în construcție (două) și pentru surse de apă sărată (unul).

\title{
3. Observații asupra toponimelor
}

Zăcămintele de sare neexploatate sînt localizate în cea mai mare parte prin indicarea localităţilor din apropiere, doar cîteva fiind localizate în apropierea cursului unui rîu, lîngă un anumit munte sau în zona unei trecători. În cazul anumitor localități (de exemplu, KIS SÁROS <KISS-SÁROS〉, comitatul Tîrnava) echivalentul românesc a fost înlocuit între timp de noile administraţii. În astfel de situaţii echivalentul românesc va fi dat ca echivalent propriu-zis, urmat de echivalentul actual (Delenii), specificat prin „azi” (KIS SÁROS <KISS-SÁROS〉, comitatul Tîrnava - Șaroșul Mic, azi Delenii, c. Băgaciu, Mureș). Toponimele apar prezentate și separat la Fichtel (1780, p. 130-134) într-un repertoriu ce precede harta, însă în unele cazuri formele nu corespund întru totul. În astfel de cazuri ele vor fi redate în paranteze unghiulare după forma din hartă. Repertoriul ce precedă harta conține și cîteva toponime ce nu se regăsesc în hartă. Acestea vor apărea în paranteze unghiulare. Atunci cînd în repertoriu apare un nume sinonim celui din hartă, se va face o intrare separată a acestuia cu trimitere la numele din hartă. În cazul variantelor sau deformărilor grafice nu se vor face trimiteri. Oiconimele din Transilvania au în repertoriu şi indicația comitatului, a scaunului sau a districtului de care aparțin, indicaţie pe care am redat-o ca atare și aici imediat după oiconim. Pentru oiconimul actual echivalent s-a indicat comuna de care aparține, folosinduse abrevierea „c." (cu excepția orașelor), urmată de numele județului. Pentru cele cîteva rîuri s-a indicat doar rîul în care acestea se varsă, cu excepția rîului Vrancea, care este un sinonim pentru cursul superior al rîului Putna. Pentru munţi și trecători s-a dat doar echivalentul actual. Pentru saline s-a dat localizarea conform nomenclaturii administrației actuale.

Toponimele vor fi ordonate alfabetic, cu indicarea toponimelor corespondente actuale, păstrînd însă redarea lor separată pentru cele trei regiuni istorice ale României.

\section{Repertoriul toponimelor cu corespondentele actuale}

\section{Țara Românească}

FOCSIAN < FOCRIAN> - Focșani, Vrancea.

OKNA KIMPINA <OKNA BEY KIMPINA> - Ocna Cîmpina, lîngă Cîmpina, Prahova.

OKNA RIMNIK <OKNA BEY RIMNIK> - Ocna Rîmnic, azi Ocnele Mari, lîngă Ocnele Mari, Vîlcea.

Teleaga <OKna teleaga > - Ocna Telega, lîngă Telega, c. Telega, Prahova.

TERGOVISTA < TERGOVIST > - Tîrgoviște, Dîmbovița.

\author{
Moldova \\ GrozeSD - Grozești, azi Oituz, c. Oituz, Bacău. \\ HERSAN - Hîrja, c. Oituz, Bacău. \\ KRUTZE <KRUTSE > - Crucea, c. Crucea, Suceava. \\ LIPSE BACH <LIPSE FLUSS> - pîrîul Lepșa, afluent stîng al rîului Putna. \\ M[ONS] KETSKETS < KECSKÉSHHAVAS> - Muntele Cheșcheș. \\ M[ONS] KIS HAVAS < KISS HAVAS > - Muntele Haoșul Mic. \\ $\mathrm{M}[\mathrm{ONS}]$ SIROS - Muntele Jiroș. \\ OJTOS FL[Uss] - pîrîul Oituz, afluent drept al rîului Trotuș. \\ OKNA <MOLDAUISCH OKNA> - Ocna Moldovei, azi Salina Tîrgu Ocna, lîngă Tîrgu Ocna, Bacău. \\ PASSUS GYÉMES - Pasul Ghimeș. \\ PASSUS OJTOS - Pasul Oituz. \\ PURTIESTJ < PORTIESTI > - Pîrteștii [de Sus], c. Cacica, Suceava.
}


SZLATINA <Slatina - Slatina, c. Slatina, Suceava.

SZUTSAVITZA <SZUTSOVITZA > Sucevița, c. Sucevița, Suceava.

VARANTZA PUTNA FL[USS] <WRANTSA PUTNA FLUSS > rîul Vrancea, cursul superior al rîului Putna.

ZABOLA PUTNA FLUSS - pîrîul Zăbala, afluent drept al rîului Putna.

\section{Transilvania}

$<$ ALSO-BORGO > veZi J[OSENI?] BORGO.

A[LSÓ] IDETS, comitatul Turda - Ideciul de Jos, c. Ideciul de Jos, Mureș.

<ALSO-RÁKOSD>, comitatul Alba - Racoșul de Jos, c. Rupea, Brașov.

A[LSÓ] SUK <ALSO-SUG >, comitatul Cluj - Jucu de Jos, c. Jucu, Cluj.

ABOCSFALVA <ABOSFALVA>, scaunul Odorhei - Aldea, c. Mărtiniş, Harghita.

ALMAS, scaunul Odorhei - Merești, c. Merești, Harghita.

ASZN BESZTERIZE <ASZU BESZLERCZE>, districtul Bistrița - Dorolea, c. Livezile, Bistrița Năsăud.

BALASF $[\hat{A}]$ L[VA], comitatul Dăbîca - Blăjenii de Jos, c. Șintereag, Bistrița Năsăud.

BALLA, comitatul Turda - Băla, c. Băla, Mureș.

BATos, comitatul Cluj - Batoș, c. Batoș, Mureș.

BELLÁK <BILlAK>, comitatul Dăbîca - Bileag, azi Domnești, c. Mărișelu, Bistrița Năsăud.

BETHLEN, comitatul Solnocul Interior - Beclean [pe Someș], Bistrița Năsăud.

BONTZ NYIRES <BONCZ-NYIRES>, comitatul Dăbîca - Bonț, c. Fizeșu Gherlii, Cluj.

BORZAS, comitatul Tîrnava - Boziaș, cartier al orașului Tîrnăveni, Mureș.

BÖZzOD <BÖSÖSD>, scaunul Odorhei - Bezid, suburbie a orașului Sîngeorgiu de Pădure, Mureș.

<BUZAS-BOCSARD>, comitatul Alba - Bucerdea Grînoasă, c. Bucerdea Grînoasă, Alba.

CSEPAN, comitatul Solnocul Interior - Cepan, azi Cepari, c. Dumitra, Bistrița Năsăud.

DEES, comitatul Solnocul Interior - Dej, Cluj.

DEESÖKNA <DESAKNA >, comitatul Solnocul Interior - Ocna Dejului, localitate componentă a orașului

Dej, Cluj.

DEZMER <DESMÉR>, comitatul Cluj - Dezmir, c. Apahida, Cluj.

$<$ DÖGMEZÖ >, vezi K[IS] DÖGMEZÖ.

DRAGOM[IRFA $]$ LV $[\mathrm{A}]$ <DRAGOMIR>, comitatul Maramureș - Dragomirești, Maramureș.

ERDÖ SZAKAL <ERDÖSSAKAL >, comitatul Turda - Săcalu de Pădure, c. Brîmcovenești, Mureș.

FEJEREGYHAZ <FEHÉREGYHÁZA〉, districtul Bistrița - Albeștii Bistriței, c. Galații Bistriței, Bistrița Năsăud.

FeKeTelak, comitatul Dăbîca - Negrenii de Cîmpie, c. Band, Mureș.

FELSÖ BAJOM, scaunul Mediaș - Boianul de Sus, azi Bazna, c. Bazna, Sibiu.

F[ELSÖ] BORGO, comitatul Dăbîca - Susenii Bîrgăului, c. Prundu Bîrgăului, Bistrița Năsăud.

F[ELSÖ] SUK <FELSÖ-SUG >, comitatul Cluj - Jucu de Sus, c. Jucu, Cluj.

$<$ FIATFALVA>, scaunul Odorhei - Filiași, suburbie a orașului Cristuru Secuiesc, Harghita.

FÜGE, comitatul Solnocul Interior - Figa, suburbie a orașului Beclean [pe Someș], Bistrița Năsăud.

GALD, scaunul Rupea - Ungra, c. Ungra, Brașov.

<GALFALVA>, comitatul Tîrnava - Gănești, c. Gănești, Mureș.

GARAD (magh. Garat, după germ. Stein), scaunul Rupea - Ștena, azi Dacia, c. Jibert, Brașov.

GRID, comitatul Hunedoara - Grid, c. Pîrău, Brașov.

<GÜRGENY-GROSZFALU (= Görgény Oroszfalu)>, comitatul Turda - Solovăstru, c. Solovăstru, Mureș.

GYEPES < KOPIS〉, scaunul Odorhei - Ghipeș, c. Mărtiniş, Harghita.

HADAT, comitatul Solnocul Interior - Hodod, c. Hodod, Satu Mare.

HESDAAD < HÉSDÁT>, comitatul Turda - Hășdate, c. Săvădisla, Cluj.

HESTAD < HÉSDÁT>, comitatul Dăbîca - Hășdate, suburbie a orașului Gherla, Cluj.

HOLDAU <HELTAU>, scaunul Sibiu - Cisnădie, Sibiu.

$<$ IKLOD $>$, comitatul Alba - Iclod, c. Sîncel, Alba. 
JAD $<$ IAAD >, districtul Bistrița - Livezile, c. Livezile, Bistrița Năsăud.

J[OSENI?] BORGO, <ALSO-BORGO>, comitatul Dăbîca - Josenii Bîrgăului, c. Josenii Bîrgăului, Bistrița Năsăud.

KAILA <KAYLA>, comitatul Dăbîca - Caila, c. Șintereag, Bistrița Năsăud.

KARATSONFALVA, scaunul Odorhei - Crăciunel, c. Ocland, Harghita.

KEMENYFALVA < HOMOROD-KEMÉNYFALVA>, scaunul Odorhei - Chemenfalău Homorodului, azi Comănești, c. Mărtiniș, Harghita.

KeNDTELKe <KENTELKE>, comitatul Dăbîca - Chintelnic, c. Șieu-Măgheruş, Bistrița Năsăud.

Kereszturf $[\mathrm{A}] \mathrm{L}[\mathrm{VA}]$, scaunul Odorhei - Cristuru, azi inclus în orașul Cristuru Secuiesc, Harghita.

KINTSES, comitatul Turda - Comori, c. Gurghiu, Mureș.

KIS AKNA, comitatul Alba de Jos - Ocniş̧oara, c. Lopadea Nouă, Alba.

K[IS] DÖGMEZÖ < DÖGMEZÖ>, comitatul Solnocul Interior - Dumbrăvița, c. Spermezeu, Bistrița Năsăud.

K[IS] KAIAN < KIS-KAJON>, comitatul Solnocul Interior - Căianu Mic, c. Căianu Mic, Bistrița Năsăud. KIS SÁROS <KISS-SÁROS>, comitatul Tîrnava - Șaroșul Mic, azi Delenii, c. Băgaciu, Mureș.

KISFALU, comitatul Dăbîca - Măgurele, c. Mărișelu, Bistrița Năsăud.

$<$ KISS-AlmaS〉, comitatul Alba - Almașul Mic de Munte, c. Balșa, Hunedoara.

< KISS-OESKÜLlÖ>, comitatul Dăbîca - Așchileu Mic, c. Așchileu, Cluj.

Kólos, comitatul Cluj - Cojocna, c. Cojocna, Cluj.

KOROND, scaunul Odorhei - Corund, c. Corund, Harghita.

KÖSZv[ÉNYES] <KÖSSVÉNYES〉, scaunul Mureș - Eremitu, c. Eremitu, Mureș.

KÖTELEND, comitatul Cluj - Gădălin, c. Jucu, Cluj.

KÖvAR, districtul Chioar - [Cetatea] Chioar[ului], lîngă Berchezoaia, c. Remetea Chioarului, Maramureș.

KÖZEPF $[\mathrm{A}] \mathrm{L}[\mathrm{VA}]$, comitatul Solnocul Interior - Chiuza, c. Chiuza, Bistrița Năsăud.

KUKÜLlÖ KEMENYF[AL]v[A], scaunul Odorhei - Tîrnovița, c. Brădești, Harghita.

KÜKÜLlovar, comitatul Tîrnava - Cetatea de Baltă, c. Cetatea de Baltă, Alba.

LÉTKA, districtul Chioar - Letca, c. Letca, Sălaj.

LÖVETE, scaunul Odorhei - Lueta, c. Lueta, Harghita.

<MAGOSMART >, comitatul Solnocul Interior - Mogoșeni, c. Nimigea, Bistrița Năsăud.

MAGYAROS, comitatul Dăbîca - Măgheruș, azi Șieu-Măgheruș, c. Șieu-Măgheruș, Bistrița Năsăud.

MAgYaros, comitatul Turda - Aluniş, c. Aluniș, Mureș.

MALlOMARKA <MALOMÁRKA>, districtul Bistrița - Monariu, c. Budacu de Jos, Bistrița Năsăud.

MÁLON <MALOM〉, comitatul Solnocul Interior - Malin, c. Nușeni, Bistrița Năsăud.

MAROS UIVAR <MAROSUJVAR>, comitatul Alba - Ocna Mureș, Alba.

MEZÖ MADARAS, scaunul Mureș - Fînațele Mădărașului, c. Mădăraș, Mureș.

MIHALIKA, comitatul Maramureș - Ocna Mihai, lîngă Ocna Șugatag, c. Ocna Șugatag, Maramureș.

MIKeHAZO <MIKEHAZA>, comitatul Solnocul Interior - Mica, c. Mica, Cluj.

MIKES, comitatul Turda - Micești, c. Tureni, Cluj.

N[AGy] Demeter, districtul Bistrița - Dumitra Mare, azi Dumitra, c. Dumitra, Bistrița Năsăud.

NAGY ERNYE <NAGY-ERENYE >, scaunul Mureș - Ernei, c. Ernei, Mureș.

N[AGY] IDA, comitatul Cluj - Ida Mare, azi Viile Tecii, c. Teaca, Bistrița Năsăud.

<NAGY-KAJON>, comitatul Solnocul Interior - Căianu Mare, c. Căianu Mic, Bistrița Năsăud.

NAGY-LOZNA <NAGY LÓSSNA〉, comitatul Solnocul Interior - Lozna, c. Lozna, Sălaj.

N[AGY] OSKÜLla <NAGY OeSKÜLlo>, comitatul Dăbîca - Așchileu Mare, c. Așchileu, Cluj.

NEMEGYE <MAGYAR-NEMEGYE și OLAH-NEMEGYE〉, comitatul Solnocul Interior - Nimigea Ungurească, azi Nimigea de Jos, și Nimigea Romînească, azi Nimigea de Sus, c. Nimigea, Bistriţa Năsăud.

NET <NÉZ >, comitatul Dăbîca - Neț, azi Nețeni, c. Mărișelu, Bistrița Năsăud.

$<$ OLAH PINTEK>, comitatul Cluj - Pintic, suburbie a orașului Dej, Cluj. 
OKNITZA <SZASZAKNA>, comitatul Cluj - Ocnița, c. Teaca, Bistrița Năsăud.

<OROSZ-BORGO>, veZi RUSZ-BORGO.

ORsova, comitatul Turda - Orșova, c. Gurghiu, Mureș.

OVASZFALA <GÖRGÉNI-OROSZFALU> [= Oroszfája], comitatul Turda - Orosfaia, c. Milaș, Bistrița Năsăud.

PARAJD < PARAYD>, scaunul Odorhei - Praid, c. Praid, Harghita.

PASSUS BOOZA - Pasul Buzău.

PASSUS RODNA - Pasul Rodna.

PAss[us] TÖmÖs - Pasul Timiş, azi Pasul Predeal.

PASSUS TORZBURG - Pasul Bran (Torzburg - Turciu, azi Bran, c. Bran, Brașov).

PASZMOS < PASSMOS〉, comitatul Cluj - Posmuș, c. Șieu, Bistrița Năsăud.

PATA, comitatul Cluj - Pata, c. Apahida, Cluj.

PERSAN, comitatul Hunedoara - Perșani, c. Șinca, Brașov.

<PETERfalva >, comitatul Tîrnava - Petrisat, suburbie a orașului Blaj, Alba.

peterfalva, comitatul Alba - Petiș, c. Șeica Mare, Sibiu.

PINTAK <SZASZ-PINTEK>, districtul Bistriţa - Pinticu, c. Teaca, Bistrița Năsăud.

REMETE, districtul Chioar - Remetea Chioarului, c. Remetea Chioarului, Maramureș.

REMETE, scaunul Mureș - Remetea, suburbie a orașului Tîrgu Mureș, Mureș.

REPS, scaunul Rupea - Rupea, Brașov.

RETSENYED, scaunul Odorhei - Rareș, c. Mărtiniș, Harghita.

RHENASZEK <RHONASZEK>, comitatul Maramureș - Coștiui, c. Rona de Sus, Maramureș.

ROTHE THURN PASS[US] - Pasul Turnul Roșu.

RUSZ-BORGO <OROSZ-BORGO>, comitatul Dăbîca - Rusul Bîrgăului, c. Prundul Bîrgăului, Bistrița Năsăud.

<SAJO KeRESSTUR>, comitatul Dăbîca - Cristur-Șieu, c. Șieu-Odorhei, Bistrița Năsăud.

<SAJO-UDVARHELY>, comitatul Solnocul Interior - Șieu-Odorhei, c. Șieu-Odorhei, Bistrița Năsăud.

SAMSAND <SAMSON>, scaunul Mureș - Șamșond, azi Șincai, c. Șincai, Mureș.

SEPTER, comitatul Cluj - Șopteriu, c. Urmeniș, Bistrița Năsăud.

$<$ SOAKNA $>$, veZi SZABANITZA.

SOM KER $[$ EK] <SOMKEREK>, comitatul Solnocul Interior - Șintereag, c. Șintereag, Bistrița Năsăud.

SOMKUT, comitatul Solnocul Interior - Șomcutul Mic, suburbie a orașului Dej, Cluj.

SOOFALVA < SÓfalVA>, scaunul Odorhei - Ocna, azi Ocna de Sus și Ocna de Jos, c. Praid, Harghita.

SOSPATAK <SOOSPATAK> comitatul Turda - Șăușa, suburbie a orașului Ungheni, Mureș.

SOVAROD, scaunul Mureș - Sovarod, c. Sovarod, Mureș.

szabaD, scaunul Mureș - Săbed, c. Ceaușu de Cîmpie, Mureș.

SZABANITZA < SOAKNA (= Görgénysóakna) >, comitatul Turda - Jabenița, c. Solovăstru, Mureș.

SZ[Ász] NYIRES, comitatul Solnocul Interior - Nireş, c. Mica, Cluj.

$<$ SZASZ-PINTEK>, veZI PINTAK.

SZASZ REGEN, comitatul Turda - Reghinul Săsesc, azi Reghin, Mureș.

$<$ SZASZAKNA〉, veZi OKNITZA.

SZEK, comitatul Dăbîca - Sic, c. Sic, Cluj.

<SZENT-ANDRÁS>, comitatul Dăbîca - Șieu-Sfîntu, c. Șintereag, Bistrița Năsăud.

S[ZEN]T IMREH <GÖRGÉNI-SZENT IMRE/SZENT-IMRE〉, comitatul Turda - Sîntimbru, c. Sîntimbru, Harghita.

s[ZENT] MARGitTA, comitatul Solnocul Interior - Sînmărghita, c. Mica, Cluj.

Sz[ENT] Marton, scaunul Ciuc - Sînmartin, c. Sînmartin, Harghita.

<SZENT-MARTON>, comitatul Turda - Mărtinești, c. Tureni, Cluj.

S[ZEN]T MARTON < HOMOROD-SZENT MÁRTON>, scaunul Odorhei - Mărtiniș, c. Mărtiniș, Harghita.

S[ZEN]T MIKLOS <SCENT MIKLOS>, comitatul Tîrnava - Sînmiclăuş, c. Şona, Alba. 
SZ[EN]T PALL < HOMOROD-SZENT PAL>, scaunul Odorhei - Sînpaul, c. Mărtiniş, Harghita.

S[ZEN]T PETER < HOMOROD-SZEnt PÉTER>, scaunul Odorhei - Petreni, c. Mărtiniş, Harghita.

SZEPLAK, comitatul Solnocul Interior - Bunești, c. Mintiu Gherlii, Cluj.

<SZESZARMA>, comitatul Solnocul Interior - Săsarm, c. Chiuza, Bistrița Năsăud.

SZIMONTElKe <Simontelke>, comitatul Dăbîca - Simionești, c. Budacu de Jos, Bistrița Năsăud.

SZITAS KerESZTUR, scaunul Odorhei - Cristuru Secuiesc, Harghita.

Szombattelke, comitatul Dăbîca - Sîmboieni, c. Sînmărtin, Cluj.

SZOTELKe <SÓTElKe>, comitatul Dăbîca - Sărata, c. Panticeu, Cluj.

SZOTZ BANYITZA <SZASZ-BANITZA>, comitatul Cluj - Băița, c. Lunca, Mureș.

SZOVATHA <SZOVATA , scaunul Odorhei - Sovata, Mureș.

TEKE <TEKENDORFF>, comitatul Cluj - Teaca, c. Teaca, Bistrița Năsăud.

THORDA, comitatul Turda - Turda, Cluj.

TOHAT, comitatul Alba de Jos - Tohat, suburbie a orașului Ulmeni, Maramureș.

TOHAT, comitatul Solnocul Interior - Tăure, c. Nimigea, Bistrița Năsăud.

TOR[PÉNY] <TREPPEN>, districtul Bistrița - Tărpiu, c. Dumitra, Bistrița Năsăud.

$<$ TREPPEN>, veZi TOR[PÉNY].

udVARHELLY, scaunul Odorhei - Odorheiu Secuiesc, Harghita.

VAJOLA <WOJOLA >, comitatul Cluj - Voila, azi Uila, c. Batoș, Mureș.

VET <WETS〉, comitatul Turda - Brîncovenești, c. Brîncovenești, Mureș.

VINDA <WAAD>, districtul Bistrița - Vinda, azi Ghinda, localitate componentă a orașului Bistrița, Bistrița

Năsăud.

<VIRÁGOSBEREK>, comitatul Solnocul Interior - Vireag, azi Florești, Bistrița Năsăud.

Viszakna, comitatul Alba de Jos - Ocna Sibiului, Sibiu.

ZEREDFADA <SZERETFALVA>, comitatul Dăbîca - Serețel, azi Sărățel, c. Șieu-Măgheruș, Bistrița Năsăud.

\section{Mine de sare, depozite sedimentare de sare și izvoare saline}

Repertoriul ce precede harta este organizat și în funcție de tipul de zăcămînt, precum și de existența ocnelor, însă fără a se specifica și numărul lor. Fichtel a și făcut observația asupra acestui amănunt și a dificultății de a indica un număr exact de zăcăminte, aşa cum o arată în prezentarea ocnelor de la Visakna (Fichtel, 1780, p. 89-90, vezi supra, \$2). Totuși, în hartă sînt indicate adesea mai multe izvoare de apă sărată („Salzbrunnen”, adică izvoare sau fîntîni) sau sedimente neexploatate. Pentru ca datele furnizate de Fichtel să poată fi utilizate în identificarea izvoarelor de apă sărată, precum și a sedimentelor de sare neexploatate, acestea vor fi enumerate alfabetic, preluînd formele deja prezentate. Pentru cele ce nu apar decît în hartă s-a dat între paranteze specificarea „doar harta” și numărul de izvoare saline sau depozite sedimentare de sare indicate. Pentru zonele ce nu apar în secțiunea de hartă din Anexa A s-a specificat numărul de izvoare saline sau depozite sedimentare de sare, dacă acestea au fost deja încadrate la secțiunea respectivă (pentru izvoare saline „Salzbrunnen”, respectiv depozite sedimentare de sare neexploatate „Salzspurien”). Pentru aceleași zone, dacă în cazul unui toponim ce apare în repertoriu doar la o categorie, iar harta indică și existența unui zăcămînt din altă categorie, s-a specificat „,harta” și numărul de izvoare saline sau, după caz, depozite sedimentare de sare. Ocnele au fost semnalate întotdeauna printr-un singur simbol. În celelalte cazuri, pentru numărul de izvoare saline sau depozite sedimentare de sare neexploatate sau cazurile în care harta oferă și alte informații față de cele din repertoriu și reluate ca atare mai sus, se poate consulta secțiunea de hartă din Anexa A.

Țara Românească

Mine de sare („Salzgruben”): OKNA KIMPINA <OKNA BEY KIMPINA〉, OKNA RIMNIK <OKNA BEY RIMNIK>, TELEAGA $\langle$ OKNA TELEAGA $>$. 
Depozite sedimentare de sare („Salzspurien”): FOCSIAN <FOCRIAN〉 (un depozit sedimentar), TERGOVISTA < TERGOVIST > (un depozit sedimentar).

Izvoare saline („Salzbrunnen”): FOCSIAN < FOCRIAN> (harta, un izvor salin), OKNA KIMPINA <OKNA BEY KIMPINA> (harta, două izvoare saline), OKNA RIMNIK <OKNA BEY RIMNIK> (harta, două izvoare saline).

\section{Moldova}

Mine de sare („Salzgruben”): OKNA <MOLDAUISCH OKNA〉.

Depozite sedimentare de sare („Salzspurien”): GROZESD (un depozit sedimentar), HERSAN (doar harta, un depozit sedimentar), M[ONS] KETSKETS <KECSKÉSHHAVAS > (un depozit sedimentar), M[ONS] KIS HAVAS <KISS HAVAS> (depozit sedimentar nesemnalat), M[ONS] SIROS (doar harta, un depozit sedimentar), VRANTZA PUTNA FL[USS] <VRANTSA PUTNA FLUSS> (doar un izvor salin, depozit sedimentar nesemnalat).

Izvoare saline („Salzbrunnen”): GROZESD (harta, un izvor salin), HERSAN (doar harta, un izvor salin), KRUTZE <KRUTSE> (două izvoare saline), M[ONS] KIS HAVAS < KISS HAVAS> (doar un izvor salin, depozit sedimentar nesemnalat), OJTOS FL[USS] (doar harta, un izvor salin), OKNA <MOLDAUISCH OKNA> (un izvor salin), PASSUS GYÉMES (doar harta, un izvor salin), PASSUS OJTOS (doar harta, un izvor salin), PURTIESTJ <PORTIESTI> (două izvoare saline), SZLATINA <SLATINA> (două izvoare saline), SZUTSAVITZA <SZUTSOVITZA> (două izvoare saline), VRANTZA PUTNA FL[USS] <VRANTSA PUTNA FLUSS> (doar un izvor salin, depozit sedimentar nesemnalat), ZABOLA PUTNA FLUSS (două izvoare saline).

\section{Transilvania}

Mine de sare („Salzgruben”): DEESÖKNA 〈DESAKNA〉, KÓLOS, PARAJD <PARAYD〉, RHENASZEK $<$ RHONASZEK>, SZEK, THORDA, VISZAKNA.

Depozite sedimentare de sare („Salzspurien”): A[LSÓ] IDETS, A[LSÓ] SUK <ALSO-SUG>, BELLÁK <BILLAK>, DRAGOM[IRFA]LV[A] <DRAGOMIR>, F[ELSÖ] SUK <FELSÖ-SUG〉, FELSÖ BAJOM, KOROND, KÖTELEND, KÖVAR (harta, un depozit sedimentar), KUKÜLLÖ KEMENYF[AL]V[A], LIPSE BACH <LIPSE FLUSS> (depozit sedimentar nesemnalat), MAROS UIVAR <MAROSUJVAR>, MIHALIKA, NAGY ERNYE <NAGY-ERENYE〉, <OLAH PINTEK>, ORSOVA, OVASZFALA <GÖRGÉNI-OROSZFALU>, PASZMOS <PASSMOS >, PATA, REMETE, districtul Chioar (harta, un depozit sedimentar), <PETERFALVA> (comitatul Tîrnava), <SAJO-UDVARHELY> (inclus incorect în comitatul Dăbîca), $s$ [ZEN]T IMREH <GÖRGÉNISZENT IMRE/SZENT-IMRE〉, SOOFALVA <SÓFALVA>, SZ[ÁSZ] NYIRES, SZ[EN]T PALL <HOMORODSZENT PAL〉, SZABANITZA <SOAKNA〉, SZASZ REGEN, SZEPLAK (harta, un depozit sedimentar), SZOVATHA <SZOVATA>, TEKE <TEKENDORFF>, UDVARHELLY, VRANTZA PUTNA FL[USS] <VRANTSA PUTNA FLUSS $>$ (depozit sedimentar nesemnalat), ZABOLA PUTNA FLUSS (trei depozite sedimentare).

Izvoare saline (,Salzbrunnen”): A[LSÓ] IDETS, <ALSO-RÁKOSD>, A[LSÓ] SUK <ALSO-SUG>, ABOCSFALVA <ABOSFALVA>, ALMAS, ASZN BESZTERIZE <ASZU BESZLERCZE〉, BALASF[Á]L[VA], BALLA, BATOS, BELLÁK <BILLAK〉, BETHLEN, BONTZ NYIRES <BONCZ-NYIRES>, BORZAS, BÖZZOD <BÖSÖSD>, <BUZAS-BOCSARD>, CSEPAN, DEES, DEZMER 〈DESMÉR>, ERDÖ SZAKAL <ERDÖSSAKAL〉, F[ELSÖ] BORGO, F[ELSÖ] SUK <FELSÖ-SUG〉, FEJEREGYHAZ <FEHÉREGYHÁZA〉, FEKETELAK, FELSÖ BAJOM, $<$ FIATFALVA>, FÜGE, GALD, <GALFALVA>, GARAD, GRID (doar harta, două izvoare saline), GYEPES < KOPIS >, HADAT (două izvoare saline), HESDAAD < HÉSDÁT >, HESTAD < HÉSDÁT >, HOLDAU < HELTAU> (cu indicația „ist vertilget“ [este epuizată]), 〈IKLOD>, J[OSENI?] BORGO, <ALSO-BORGO>, JAD 〈IAAD>, KAILA < KAYLA>, KARATSONFALVA, KEMENYFALVA < HOMOROD-KEMÉNYFALVA>, KENDTELKE < KENTELKE>, KERESZTURF[A]L[VA], KINTSES, KIS AKNA (doar harta, două izvoare saline), K[IS] DÖGMEZÖ <DÖGMEZÖ >, K[IS] KAIAN < KIS-KAJON>, KIS SÁROS < KISS-SÁROS >, KISFALU (doar harta, două izvoare saline), <KISS-ALMAS>, <KISS-OESKÜLLÖ>, KOROND, KÖSZV[ÉNYES] < KÖSSVÉNYES>, KÖTELEND, KÖVAR (doar harta, un izvor salin), KÖZEPF[A]L[VA], KÜKÜLLOVAR, LÉTKA, LÖVETE, 〈MAGOSMART>, 
MAgYaros (comitatul Dăbîca), MAgYaros (comitatul Turda), MALlOMARKa <MALOMÁRKA>, MÁLON <MALOM>, MAROS UIVAR <MAROSUJVAR>, MEZÖ MADARAS, MIKEHAZO <MIKEHAZA>, MIKES, N[AGY] DEMETER, NAGY ERNYE <NAGY-ERENYE〉, N[AGY] IDA, <NAGY-KAJON>, NAGY LOZNA <NAGY LÓSSNA〉, N[AGY] OSKÜLLA <NAGY OESKÜLLO〉, NEMEGYE <MAGYAR-NEMEGYE AND OLAHNEMEGYE>, NET <NÉZ>, OKNITZA <SZASZAKNA>, <OLAH PINTEK>, ORSOVA, OVASZFALA <GÖRGÉNIOROSZFALU> [= Oroszfája], PASSUS BOOZA (doar harta, un izvor salin), PASSUS RODNA (doar harta, un izvor salin), PASS[US] TÖMÖs (doar harta, un izvor salin), PASSUS TORZBURG (doar harta, un izvor salin), PASZMOS <PASSMOS>, PERSAN (doar harta, două izvoare saline), PETERFALVA (comitatul Alba), PINTAK <SZASZ-PINTEK>, REMETE (districtul Chioar), REMETE (scaunul Mureș), REPS, RETSENYED, ROTHE THURN PASS[US] (doar harta, un izvor salin), RUSZ-BORGO 〈OROSZ-BORGO〉, 〈SAJO KERESSTUR>, 〈SAJO-UDVARHELY>, SAMSAND <SAMSON>, SEPTER, SOM KER[EK] 〈SOMKEREK〉, SOMKUT, SOOFALVA <SÓFALVA>, SOSPATAK <SOOSPATAK>, SOVAROD, SZABAD, SZABANITZA <SOAKNA〉, SZEPLAK (un izvor salin), SZ[ÁSZ] NYIRES, 〈SZENT-ANDRÁS>, S[ZEN]T IMREH <GÖRGÉNI-SZENT IMRE/ SZENT-IMRE〉, S[ZENT] MARGITTA, SZ[ENT] MARTON (scaunul Ciuc), <SZENT-MARTON> (comitatul Turda), sZ[ENT] MARTON <HOMOROD-SZENT MÁRTON〉, S[ZEN]T MIKLOS <SCENT MIKLOS >, S[ZEN]T PETER < HOMOROD-SZENT PÉTER>, <SZESZARMA>, SZIMONTELKE <SIMONTELKE〉, SZITAS KERESZTUR, SZOMBATTELKE, SZOTELKE <SÓTELKE>, SZOTZ BANYITZA <SZASZ-BANITZA>, TEKE <TEKENDORFF $>$, TOHAT (comitatul Solnocul Interior), TOHAT (comitatul Alba de Jos; doar harta, două izvoare saline), TOR[PÉNY] 〈TREPPEN>, UDVARHELLY, VAJOLA 〈WOJOLA〉, VET 〈WETS〉, VINDA 〈WAAD>, $<$ VIRÁGOSBEREK>, ZEREDFADA <SZERETFALVA>.

\section{Concluzii}

Identificarea corespondentelor actuale ale toponimelor din harta lui Fichtel este doar un scop-mijloc. Rezultatele devin un material disponibil pentru cercetarea istoriei exploatării sării pe teritoriul României, îndeosebi pentru regiunea Transilvaniei. O monografie dedicată istoriei salinelor din epoca modernă a Moldovei a fost realizată de Vitcu (1987). Exploatarea sării în Transilvania oferă o istorie mult mai bogată, iar unul dintre paşii necesari este această echivalare a nomenclaturii din perioada administraţiei maghiare cu cea actuală. Obiectivul lucrării de faţă nu a inclus și explicarea unor variante care nu sînt simple deformări grafice, cum ar fi, de exemplu, variația Tergovista/ Tergovist, unde - a este articol hotărît feminin, care reprezintă acordul în gen cu cetate, sau semicalcul maghiar Orosz-Borgo și transliterarea RuszBorgo. Localizările din harta lui Fichtel (realizată în colaborare cu Carl Gabriel Wappler) au un înalt grad de exactitate pentru epoca în care a fost realizată harta. Doar trei localități sînt poziționate în mod vizibil deplasat: Szeplak (deplasat spre est) și Ovaszfala (deplasat spre sud-est) și Septer (deplasat spre nord-est). Anexa A reprezintă zona Transilvaniei din harta lui Fichtel. Mihalika a fost identificat cu Ocna Mihai, conform poziției din hartă.

\section{Bibliografie}

\section{A. Lucrări de referință}

Ackner, M.J. (1856). Die Römischen Alterthümer und deutschen Burgen in Siebenbürgen, în „Jahrbuch der Kaiserlich Königlichen Central-Comission zur Erforschung und Erhaltung der Baudenkmale", II. Abtheilung, Wien, p. 3-50.

Ackner, M.J. \& Müller, F. (1865). Die römischen Inschriften in Dacien, Tendler, Wien.

Christescu, V. (2004). Viața economică a Daciei Romane, Ars Docendi, București (ed. I-a: 1929).

Ciobanu, D. (2002). Exploatarea sării în perioada marilor migrații (sec. I-XIII e.n.) in spațiul carpato-dunărean, Biblioteca Mousaios, Buzău.

Dana, D. \& Zăgreanu, R. (2013). Deux dédicaces latines inédites de Porolissum, în „Tyche. Beiträge zur Alten Geschichte, Papyrologie und Epigraphik", vol. 28, p. 27-35, Crossref.

Doboși, A. (1951). Exploatarea ocnelor de sare din Transilvania în evul mediu (sec. XIV-XVI), în „Studii și cercetări de istorie medie", p. 125-166. 
Fichtel, I.E. von (1780). Geschichte des Steinsalzes und der Steinsalzgruben im Grossfürstenthum Siebenbürgen, mit einer, das Streichen des unterirrdischen Salzstockes, durch mehrere Länder andeuten den Karte, und andern Küpfern, Kaspischen Verlag, Nürnberg, Crossref.

Fischer, G. (1921). Zwei römische Inschriften aus Billak bei Bistritz, în „Korrespondenzblatt des Vereins für siebenbürgische Landeskunde", XLIV/7-12, p. 67-72.

Gooss, C. (1876). Chronik der archäologischen Funde Siebenbürgens, în „Archiv des Vereins für siebenbürgische Landeskunde”, 13/II, p. 203-338.

Maghiar, N. \& Olteanu, Șt. (1970). Din istoria mineritului în România, Editura Științifică, București.

Mihăilescu-Bîrliba, L. (2016). Remarques sur le personnel de l’administration des salines en Dacie Romaine, în „Studia Antiqua et Archæologica", XXII/1, p. 51-58.

Opitz, M. (2009). Briefwechsel und Lebenszeugnisse: kritische Edition mit Übersetzung, ed. Klaus Conermann, Walter de Gruyter, Berlin/New York (ed. I-a: 1611-1642).

Pascu, Șt. (1986). Voievodatul Transilvaniei, III, Editura Dacia, Cluj-Napoca.

Piso, I. (2004-2005). Un nouveau conductor salinarum en Dacie, în „Acta Musei Napocensis”, 41-42, p. 179-182.

Suciu, C. (1967). Dicționar istoric al localităților din Transilvania, vol. I-II, Editura Academiei, București.

Treuenfeld, I. L. von (1839). Siebenbürgens geographisch-, topographisch-und orographisches Lexikon, Wien.

Vitcu, D. (1987). Istoria salinelor Moldovei în epoca modernă, în „Anuarul Institutului de istorie și arheologie «A.D. Xenopol»", Supliment IX, Iași.

Wollmann, V. (1996). Mineritul metalifer, extragerea sării și carierele de piatră în Dacia Romană / Der Erzbergbau, die Salzgewinnung und die Steinbrüche in römischen Dakien, Bibliotheca Musei Napocensis, Klausenburg/Cluj-Napoca.

Zamosius, S. (1593). Analecta lapidum vetustorum et nonnullarum in Dacia antiquitatum, Pataviæ.

\section{B. Surse}

CDEM I = Codex diplomaticus et epistolaris Moravia. Tomus primus. Studio et opera Antonii Boczek, Skarnitzl, Olomucii, 1836. CIL III = Corpus Inscriptionum Latinarum. Vol. III, Inscriptiones Asie, provinciarum Europe Grecarum, Illyrici Latine, ed. Th. Mommsen, Berolini, 1873.

DIR,C I = Documente privind istoria României. C. Transilvania, veacurile XI, XII și XIII, vol. I, Editura Academiei, București, 1951.

IDR III = Inscripțiile Daciei Romane, vol. III, ed. Ioan I. Russu, Editura Academiei, București, 1984 (III/3), 1988 (III/4); ed. I. Piso, Ed. Frères Boccard, Paris, 2001 (III/5). 


\section{Anexa A.}

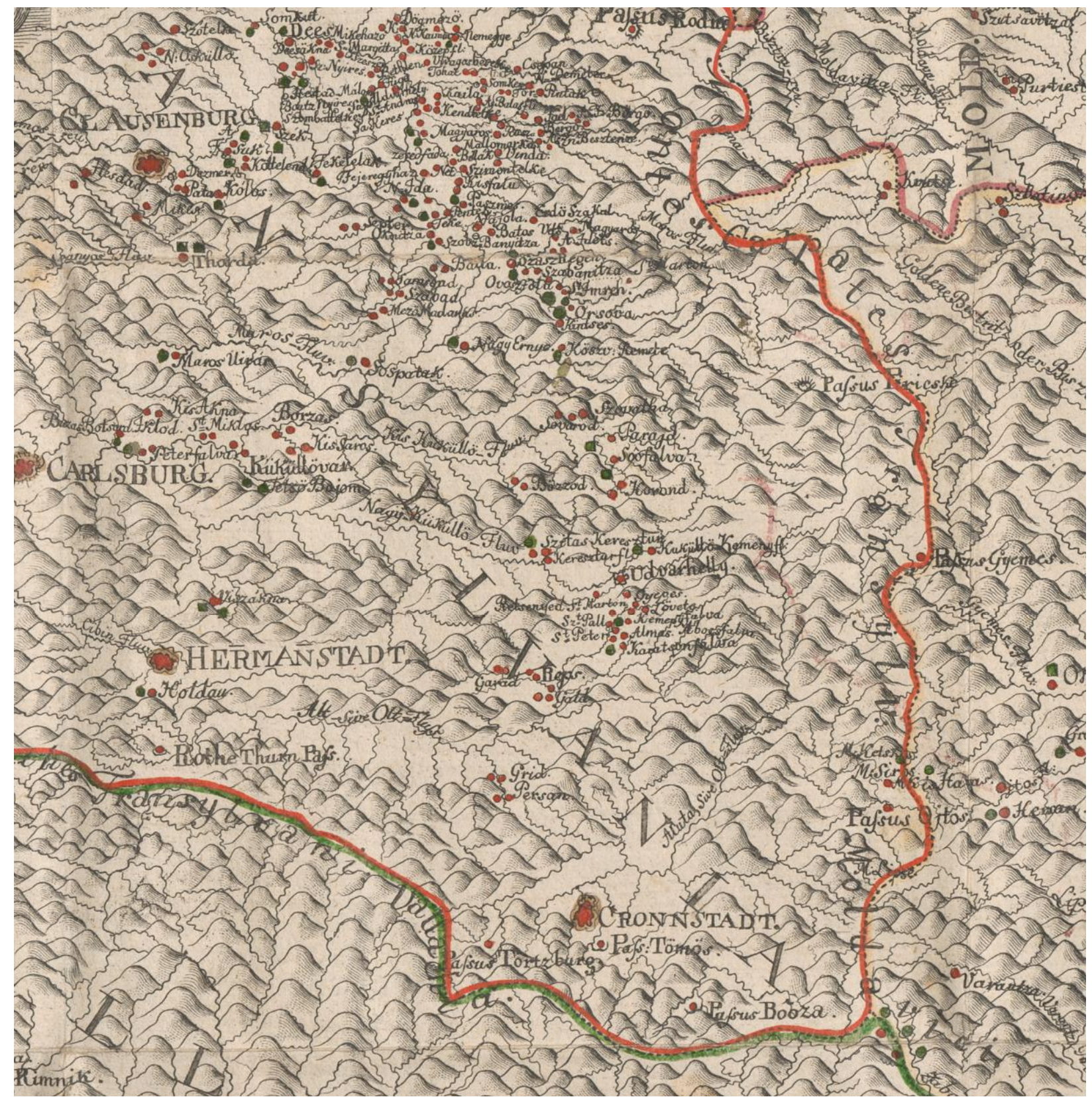

Figura A.1: Secțiune din harta lui Fichtel (PLAN der andeütet, wie der Unterirrdische-Salz-Stok, von der Wallacheÿ angefangen, durch die Wallacheÿ Moldau, Siebenbürgen, Hungarn und Pohlen, bis nach Vieliczka und Pochnia in Pohlen und bis Sowar in Hungarn längst der Karpatischen Gebürge fort streichet). 